\begin{tabular}{|c|c|c|}
\hline - T & $\begin{array}{l}\text { European Association for the } \\
\text { Development of Renewable Energies, Environment } \\
\text { and Power Quality (EA4EPQ) }\end{array}$ & $\begin{array}{l}\text { International Conference on Renewable Energies and Power Quality } \\
\text { (ICREPQ'12) } \\
\text { Santiago de Compostela (Spain), 28th to 30th March, } 2012\end{array}$ \\
\hline
\end{tabular}

\title{
Analysis and Energetic Characterization of Low-Power Grid-Connected Photovoltaic Systems
}

\author{
António P. Martins ${ }^{1}$ and Domingos M. Carvalho ${ }^{2}$ \\ ${ }^{1,2}$ Department of Electrical and Computer Engineering \\ Faculty of Engineering, University of Porto \\ Rua Dr Roberto Frias, s/n, 4200-465 Porto (Portugal) \\ Phone/Fax number: +351 225081816, e-mail: ajm@fe.up.pt
}

\begin{abstract}
This paper discusses some of the most important Photovoltaic (PV) systems characteristics related to its global efficiency like MPP tracking efficiency, static efficiency, conversion efficiency as well as the Euro efficiency. The losses models of the power semiconductors constituting the Power Electronics (PE) subsystems as well as the models of transformers and DC and AC cables are reviewed. Three topologies are selected, representing the PV market and simulation results are discussed. Given the importance of the global efficiency of an installation for the owner, recorded field results with the same systems are presented. The main conclusion is that the global efficiency of a PV installation depends not only on the PE subsystem, with or without isolation transformer in the low or high-frequency stages, but also on the $\mathrm{DC}$ and $\mathrm{AC}$ conduction losses, and on the distance of the installation to the coupling point to the electric grid.
\end{abstract}

\section{Keywords}

Cabling, Efficiency, Losses, PV inverters

\section{Introduction}

The highest efficiency reached until now in PV inverters is $98.8 \%$, and was obtained at the Fraunhofer Institute for Solar Energy Systems using silicon carbide transistors. The dissipated power in conventional inverters using silicon transistors was reduced between 30 and $50 \%$. This technology has been explored with success and the highest efficiencies have been obtained in the low power ranges, as demonstrated in [1]-[3].

However, the global efficiency of a PV system depends on other factors like DC and AC cable losses. Additionally, from the investment point of view, other aspects must be considered like the efficiency of the Maximum Power Point Tracking (MPPT) algorithm or the rating of the PE system compared to the installed PV power or the contracted power with the grid operator.
The system rating should be done in such a way that the PV inverter will be nor underutilized nor overloaded. Under-rating was identified in the beginning of the 90's as a possibility for reducing the costs of the generated $\mathrm{kWh}$, [4]. In such a way, an inverter with less capacity for the same PV generator can be used, without a significant impact on the amount of energy injected in the grid; so, the generated energy tends to be less costly.

The Inverter Design Factor (IDF) represents the relation between the inverter nominal power and the maximum PV power. Analyzing the behaviour of a single inverter is was concluded that the productivity decayed more sharply for inverters with an IDF less than 0.6, according to the limiting power condition, occurring when the available $\mathrm{PV}$ is higher than the inverter rating. Independently of the geographic location of the PV system, the losses caused by the limited inverter power are less than $10 \%$ for an IDF of 0.5 and less than $3 \%$ for an IDF of 0.6 , [4]. So, an under-rated inverter can be an interesting choice for PV systems.

\section{Efficiency Parameters for PV Systems}

Several parameters are used to characterize and determine the global efficiency of a PV system. It must be referred the DC/DC and the DC/AC conversion efficiency, and the MPP tracking efficiency. Additionally, the Euro efficiency allows classifying and comparing PV systems in different environment conditions.

\section{A. DC/AC Conversion Efficiency}

The efficiency of the DC/AC conversion characterizes losses originated by the conversion of the DC current into AC current. In PV systems, these losses include the losses originated in the transformer and in the PE switches. This efficiency can be represented by: 


$$
\eta_{C o n}=\frac{P_{A C}}{P_{D C}}
$$

where $P_{A C}$ is the power delivered at the inverter output (fundamental component) and $P_{D C}$ is the input power at inverter DC-bus.

\section{B. Tracking Efficiency}

PE converters for grid-connected PV systems assure an optimal adaptation to the PV panel I-V characteristic. The capability of a power converter for adjusting its operating point to the PV panel MPP point is described by the tracking efficiency

$$
\eta_{T r}=\frac{P_{D C}}{P_{P V}}
$$

where $P_{D C}$ is the active power supplied to a DC-bus and $P_{P V}$ is the instantaneous maximum power available in the PV panel. In the calculation of $\eta_{T r}$ it can be included the DC cable losses.

The static efficiency of a PV system is then obtained by the product of the two described efficiencies, conversion and tracking:

$$
\eta_{\text {Inv }}=\eta_{\text {Con }} \cdot \eta_{\text {Tr }}
$$

This efficiency can be determined for different load conditions. The nominal efficiency, given by manufacturers, is obtained during inverter operation in nominal conditions $\left(V_{n}\right.$ and $\left.I_{n}\right)$. The nominal scenario, and also the maximum efficiency, is only reached with certain conditions of irradiance and temperature; irradiance variations are responsible for the inverter frequent operation in partial load.

\section{Euro Efficiency}

In order to facilitate the comparison between different PV systems based on their efficiency, it was created the Euro efficiency, $\eta_{\text {Euro }}$, calculated to the European climate. To consider different load scenarios, Euro efficiency is calculated using a weighted average of different static efficiencies, defined for six load conditions (nominal and five different partial loads), according to:

$$
\begin{aligned}
\eta_{\text {Euro }}= & 0,03 \eta_{5 \%}+0,06 \eta_{10 \%}+0,13 \eta_{20 \%}+0,1 \eta_{30 \%} \\
& +0,48 \eta_{50 \%}+0,2 \eta_{100 \%}
\end{aligned}
$$

As can be verified in (4), the $\eta_{100 \%}$ value corresponds to the efficiency in the condition of nominal irradiance. The PV generator power corresponds then to the nominal inverter power $\left(P_{P V}=P_{n}\right)$. In average, it is assumed that the inverter is operating with $100 \%$ load during $20 \%$ of the time along a year, and so on. The Euro efficiency allows for the comparison of different inverters.

Extensive comparisons between inverters efficiency curves are not justified. Depending on the power rating, DC voltage level and power circuit architecture, Euro efficiency varies between $86 \%$ and $95 \%$. It is usually calculated only for the nominal voltage while PV panels operating in MPP points cover a wide voltage range. The IEC 61683 specifies three voltages for efficiency calculation: minimum input voltage, nominal, and $90 \%$ of the maximum input voltage. However, there is no standard method to calculate the weighted average of the Euro efficiency with different voltages, which turns difficult to obtain the best estimation of the real efficiency of a PV system and the establishing of comparative analysis between different systems.

\section{Performance Ratio}

Performance Ratio (PR), frequently referred as quality factor, is an important measure for evaluating the efficiency of a PV system. PR designates the relation (independent of the PV system alignment and irradiation) between the energy effectively produced and the possible theoretical one. In general, highly efficient PV systems reach a PR of nearly $80 \%$, [5]. The ideal time interval for evaluating PR is a year; however, smaller time intervals can be used. To evaluate PR, the following simplified expression can be used:

$$
P R=\frac{E_{\text {Real }}}{E_{\text {Annual }} \eta_{P V}}
$$

where $E_{\text {Real }}$ is the real energy produced in a year, $E_{\text {Anпиal }}$ is the one-year irradiation energy in the PV panels surface and $\eta_{P V}$ is the PV panels efficiency. The real energy produced in a year is measured, e.g. by an energy meter.

Environment factors like panels' temperature, solar irradiation and shadows and other factors like conduction losses, PV panels and inverter efficiency, all have influence in the PR value.

\section{E. Methods to Increase the Converters Efficiency}

The increasing of the converters power density is obtained increasing the converters switching frequency thus reducing the volume and weight of the reactive components. However, an increased switching frequency also increases semiconductor losses, mainly the switching ones, bringing the need of an increasing volume of the heat sinks. This fact reduces the possibility of reducing the converter volume. It is needed then to reduce the semiconductors voltage and current stress in order to reduce the losses. In this sense, techniques for the association of switches or converters can be used.

To reduce switching losses different resonant techniques can be used, thus achieving lossless switching. The most used ones are the Zero-Voltage Switching (ZVS) and the Zero-Current Switching (ZCS), [6].

Non-dissipative techniques minimize switching losses, enabling a higher switching frequency, but conduction losses remain. To reduce these losses a possible solution is the series or parallel association of semiconductors and converters. Also, multilevel current-source and voltagesource inverters are used in the high power range, [7].

\section{Power Electronics Losses}

The PE system efficiency is the factor that most influences the global efficiency of the PV system. In this section it is reviewed the model losses of power semiconductors, namely conduction and switching losses, in order to present simulation results related to three of the most used topologies in the low power PV market. 


\section{A. Conduction Losses}

To evaluate losses in the DC/DC converter and in the inverter it is needed the conduction and switching models of the power semiconductors and the associated operating conditions: for the DC/DC converter, input and output DC voltage and input current and, for the inverter, DC-bus voltage and output voltage and current, magnitude and phase. In both cases the switching frequency is also needed. The typical $\mathrm{I}-\mathrm{V}$ static relation of a power semiconductor (diode or transistor) is shown in Fig. 1.

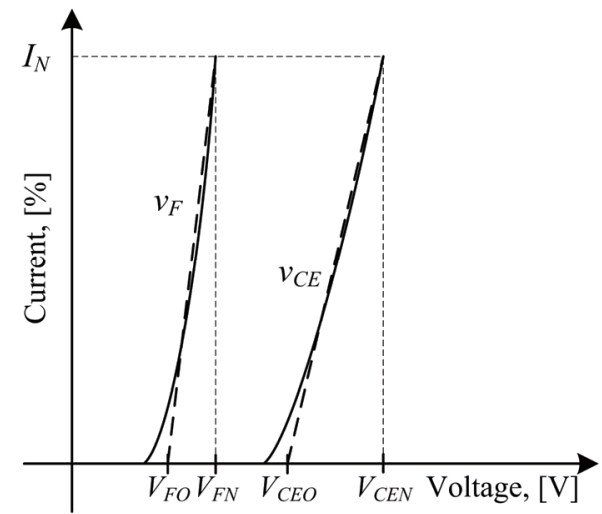

Fig. 1. Power semiconductor conduction model, transistor or diode.

For the transistor, its V-I model can be approximated by the following linear relation:

$$
v_{C E}=\frac{V_{C E N}-V_{C E O}}{I_{C N}} i_{C}+V_{C E O}
$$

where $I_{C N}$ and $V_{C E N}$ are the current and voltage nominal values in forward conduction and $V_{C E O}$ is the threshold conduction voltage, which depends on the transistor type and the nominal DC voltage.

Generally, the diode voltage drop follows an exponential law. Inside the conduction zone the curve can be approximated by a linear relation starting at $V_{F O}$ (Fig.1). This conduction threshold is variable; it depends on the particular diode technology but, typically, can be considered equal to $0.7 \mathrm{~V}$. In the same figure, $V_{F N}$ is the diode voltage drop at nominal current. So, the diode V-I relation is given by (7):

$$
v_{F}=\frac{V_{F N}-V_{F O}}{I_{C N}} i_{C}+V_{F O}
$$

If $F(\alpha)$ is the modulating function $(-1<F(\alpha)<1), \theta$ the angle between the inverter output current and the fundamental component of the inverter output voltage and $m$ the modulation index then the duty-cycle, $\delta$, of the switching pulses is given by (8):

$$
\delta=\frac{1}{2}[1+m \cdot F(\alpha+\theta)]
$$

In the case of sinusoidal modulation it results:

$$
F(\alpha+\theta)=\sin (\alpha+\theta)
$$

The need of injecting a grid current with a very low THD implies the use of high switching frequencies and an adequate filtering inductance. So, for the analysis of inverter losses, the inverter current can be considered a sine wave:

$$
i_{C}=I_{C M} \sin (\alpha)
$$

Solving the equation for the dissipated energy in the semiconductors during the conduction intervals the following results are obtained for the losses in a transistor and in a diode, [8]-[9].

$$
\begin{gathered}
P_{T}=\left(\frac{1}{8}+\frac{m}{3 \pi}\right) \frac{V_{C E N}-V_{C E O}}{I_{C N}} I_{C M}^{2}+\left(\frac{1}{2 \pi}+\frac{m}{8} \cos \theta\right) V_{C E O} I_{C M} \\
P_{D}=\left(\frac{1}{8}-\frac{m}{3 \pi}\right) \frac{V_{F N}-V_{F O}}{I_{C N}} I_{C M}^{2}+\left(\frac{1}{2 \pi}-\frac{m}{8} \cos \theta\right) V_{F O} I_{C M}
\end{gathered}
$$

These equations can be applied also to MOSFET transistors; their conduction model can be written in the same form, with $V_{C E O}=0, V_{C E N}=I_{C N} R_{D S}$.

\section{B. Turn-on and Turn-off Switching Losses}

Switching losses can be analyzed with the help of Fig. 2, where $V_{D C}$ is the DC-bus voltage and $L_{s}$ is the leakage inductance of the DC loop. It is verified that the $d i / d t$ during turn-on is approximately constant; it means that rise time is proportional to the switched current.

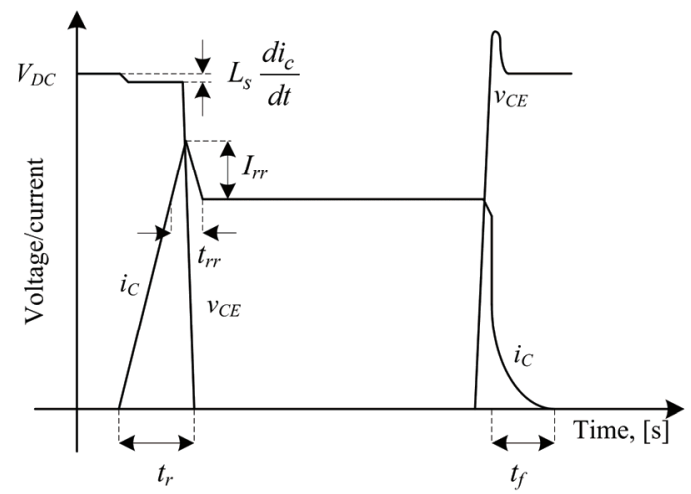

Fig. 2. Typical switching waveforms of a transistor-diode pair.

Being $F_{s}$ the switching frequency and $t_{r N}$ the nominal rise time under nominal current it can be obtained:

$$
P_{o n}=\frac{1}{8} V_{D C} t_{r N} \frac{I_{C M}^{2}}{I_{C N}} F_{S}
$$

From manufacturers catalogues and experiments it can be concluded that the fall time of the current almost does not depend on the current to be commutated but on the time the semiconductor tail current reaches zero. Simple calculations allow concluding that losses due to turn-off switching are given by (14), [8]-[9]:

$$
P_{o f f}=V_{D C} I_{C M} t_{f N} F_{S}\left(\frac{1}{3 \pi}+\frac{1}{24} \frac{I_{C M}}{I_{C N}}\right)
$$

\section{Recovery Losses}

The switching of an inductive circuit, as is the case of voltage-source inverters connected to the grid, contains an additional loss term due to the recovering of storage charges in the free-wheeling diodes (Fig. 2). In a first interval, the transistor is subjected to the DC-bus voltage and conducts the diode recovery current until it reaches its maximum value. In a second interval, when the current in 
the diode returns to zero, the diode is subjected to the DC voltage. During the two intervals losses occur in the transistor and in the diode and they can be combined in a single expression. Considering the current a sine wave, it results (15) for the losses in a transistor-diode pair, [9]:

$$
\begin{aligned}
P_{r r}= & F_{s} V_{D C}\left[\left(0,28+\frac{0,38}{\pi} \frac{I_{C M}}{I_{C N}}+0,015\left(\frac{I_{C M}}{I_{C N}}\right)^{2}\right) \times Q_{r r N}\right. \\
& \left.+\left(\frac{0,8}{\pi}+0,05 \frac{I_{C M}}{I_{C N}}\right) I_{C M} t_{r r N}\right]
\end{aligned}
$$

where $t_{r r N}$ and $Q_{r r N}$ are the nominal recovery time and recovery charge, respectively.

The inverter total losses depend on the specific topology as well as the switching method. A similar procedure can be applied to other converters existing in the PV chain, namely a DC/DC converter.

\section{Simulation Results}

The PV chain is mainly constituted by PV panels, DC cables, step-up converter, PWM inverter and AC cables. The output transformer has been or not considered according to the specific topologies used in the experiments. In the results, losses in the DC and AC cables are not included in order to allow a better comparative analysis between the three PV installations. Table I lists the main characteristics of the analysed systems: topology, power rating, PV panels arrangement and Euro efficiency.

Table I. Main characteristics of the analysed PV systems.

\begin{tabular}{lccc}
\hline \hline & Syst. I & Syst. II & Syst. III \\
\hline PV power (W) & 4320 & 4140 & 4140 \\
\hline AC power (W) & 3500 & 3680 & 3600 \\
\hline PV panels; strings & $18 ; 3$ & $18 ; 2$ & $18 ; 2$ \\
\hline PV voltage range (V) & $150-400$ & $200-400$ & $350-600$ \\
\hline DC/DC converter & Yes & No & No \\
\hline HF transformer & Yes & No & No \\
\hline Grid transformer & No & Yes & No \\
\hline Euro efficiency $(\%)$ & 93.5 & 94.7 & 95.8 \\
\hline
\end{tabular}

The topologies of the three systems are shown in Fig. 3. It was considered the presence of a MPPT algorithm based on the open circuit voltage, thus allowing the establishing of the PV panels voltage according to the supplied power, [10]. It was also admitted an inverter with a constant DCbus voltage for the topology with two conversion stages. In the others, the DC-bus voltage is variable and depends on the available PV power. So, it is established the dutycycle of the existing DC/DC converter and the modulation index and phase of the fundamental component of the inverter output voltage.

Table II shows the main parameters used to evaluate the losses in the conversion chain and Fig. 4 the results for the three considered systems. From these results it can be concluded that System I, with a two-stage conversion chain and a HF transformer, is the one with the lowest efficiency.
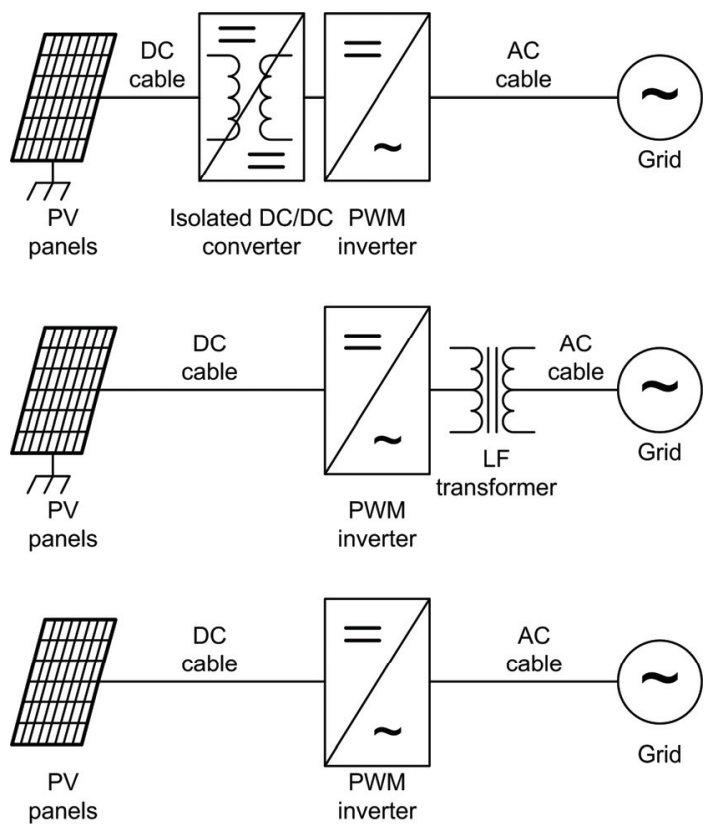

Fig. 3. Internal configuration of System I (top), System II (middle) and System III (bottom).

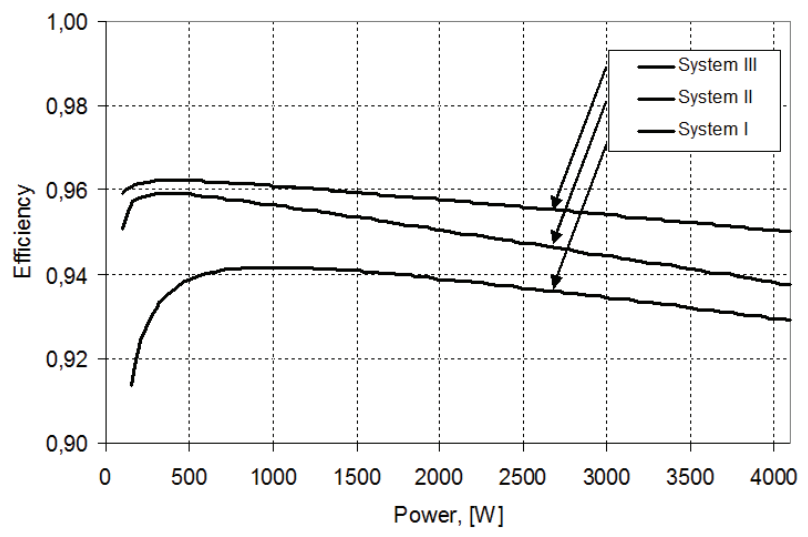

Fig. 4. Efficiency of System I, with DC/DC converter and HF transformer, System II, with grid transformer, and System III, with single stage conversion, without transformer.

System II although using a grid transformer and, consequently, isolation of the PV panels, is not particularly affected in terms of efficiency by that fact. Finally, the simplest in terms of configuration, System III is, in fact, the most efficient in what refers to energy. This fact makes that this kind of systems have gained importance in the PV market, namely where isolation is not mandatory.

However, the global efficiency of an installation does not depend exclusively on the PE system but also on the installation conditions, namely PV panels arrangement, DC cabling and connection to the electric grid. The next section will clearly demonstrate this.

\section{Experimental Results}

Besides the PE parameters already presented, the analysed PV systems were installed in different conditions, namely in DC and AC cabling from the solar panels to the point of grid coupling. Table III shows the cable arrangements in the three installations. 
Table II. Parameters used for simulation.

\begin{tabular}{lccc}
\hline \hline & System I & System II & System III \\
\hline MPP voltage & $290-340 \mathrm{~V}$ & $270-310 \mathrm{~V}$ & $350-600 \mathrm{~V}$ \\
\hline DC current: $I_{C N}$ & $22.5 \mathrm{~A}$ & $23.4 \mathrm{~A}$ & $13.2 \mathrm{~A}$ \\
\hline MOSFET: $R_{D S}$ & $0,1 \Omega$ & - & - \\
\hline Diode: $V_{F O} ; V_{F N}$ & $0.7 \mathrm{~V} ; 1.3 \mathrm{~V}$ & - & - \\
\hline Switching frequency: $F_{s}$ & $20 \mathrm{kHz}$ & - & - \\
\hline DC/DC transformer: $R_{e q}$ & $0.02 \Omega$ & - & - \\
\hline DC voltage: $V_{C C}$ & $400 \mathrm{~V}$ & $260-330 \mathrm{~V}$ & $350-540 \mathrm{~V}$ \\
\hline AC current: $I_{C N}$ & $32 \mathrm{~A}$ & $49 \mathrm{~A}$ & $32 \mathrm{~A}$ \\
\hline IGBT: $V_{C E O} ; V_{C E N}$ & $1.5 \mathrm{~V} ; 2.5 \mathrm{~V}$ & $2.9 \mathrm{~V} ; 3.2 \mathrm{~V}$ & $1.8 \mathrm{~V} ; 4.5 \mathrm{~V}$ \\
\hline Diode: $V_{F O}, V_{F N}$ & $0.5 \mathrm{~V} ; 1.0 \mathrm{~V}$ & $0.7 \mathrm{~V} ; 1.5 \mathrm{~V}$ & $1.2 \mathrm{~V} ; 2.5 \mathrm{~V}$ \\
\hline Switching frequency: $F_{s}$ & $20 \mathrm{kHz}$ & $15 \mathrm{kHz}$ & $18 \mathrm{kHz}$ \\
\hline Switching times: $t_{r N} ; t_{f N}$ & $300 \mathrm{~ns} ; 300 \mathrm{~ns}$ & $200 \mathrm{~ns} ; 200 \mathrm{~ns}$ & $400 \mathrm{~ns} ; 400 \mathrm{~ns}$ \\
\hline Recovering: $t_{r r N} ; Q_{r r N}$ & $300 \mathrm{~ns} ; 0.5 \mu \mathrm{C}$ & $200 \mathrm{~ns} ; 0.5 \mu \mathrm{C}$ & $400 \mathrm{~ns} ; 0.1 \mu \mathrm{C}$ \\
\hline Filter inductance: $L_{g} ; R_{e q}$ & $20 \mathrm{mH} ; 0.1 \Omega$ & $10 \mathrm{mH} ; 0.1 \Omega$ & $25 \mathrm{mH} ; 0.1 \Omega$ \\
\hline Grid transformer: $V_{p} / V_{s} ; R_{e q}$ & - & $150 / 230 ; 0.22 \Omega$ & - \\
\hline \hline
\end{tabular}

Table III. Cable parameters in different installations.

\begin{tabular}{lccc}
\hline \hline & Syst. I & Syst. II & Syst. III \\
\hline DC cable length $(\mathrm{m})$ & 15 & 12 & 4 \\
\hline DC cable section $\left(\mathrm{mm}^{2}\right)$ & 10 & 10 & 10 \\
\hline PV strings & 3 & 2 & 2 \\
\hline DC cable resistance $(\Omega)$ & $0.02 \Omega$ & $0.02 \Omega$ & $0.01 \Omega$ \\
\hline AC cable length $(\mathrm{m})$ & 25 & 15 & 120 \\
\hline AC cable section $\left(\mathrm{mm}^{2}\right)$ & 16 & 16 & 16 \\
\hline AC cable resistance $(\Omega)$ & $0.05 \Omega$ & $0.03 \Omega$ & $0.27 \Omega$ \\
\hline \hline
\end{tabular}

\section{A. Systems I, II and III}

The graphic in Fig. 5 shows the measured efficiency at the inverter output in function of the PV power delivered by the panels in System I, II, and III not considering the DC and $\mathrm{AC}$ cable losses.

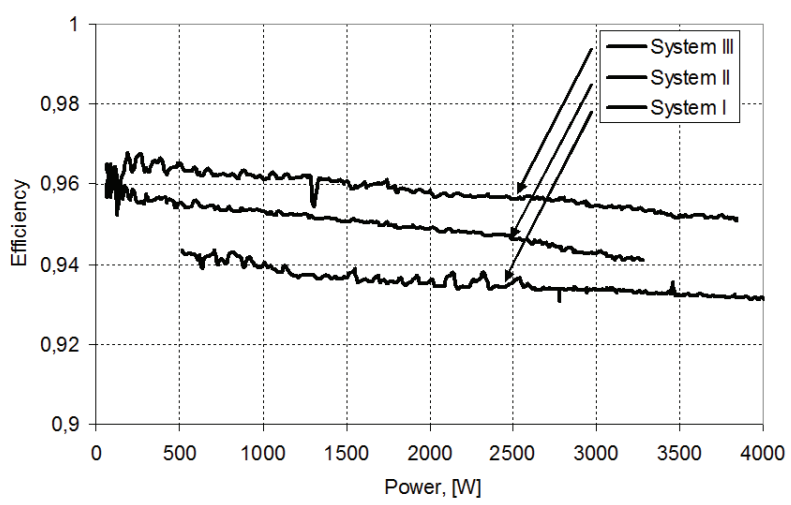

Fig. 5. Experimental recorded efficiency vs. output power for System I, System II and System III.

In the record from System I, it can be noticed that for higher powers the efficiency slightly decreases. According to the manufacturer, System I presents a maximum efficiency of $94.3 \%$ and a Euro efficiency of $93.5 \%$. For the measured results and doing a weighted average it is obtained an efficiency of $93.72 \%$, close to the manufacturer data. For the used DC and AC cabling it can be estimated losses of $0.07 \%$ and $0.37 \%$, respectively, at nominal power.
For System II, as in System I, it can be noticed a decreasing efficiency for higher output powers. From the manufacturer, this inverter has a maximum efficiency of $95.6 \%$ and a Euro efficiency of $94.7 \%$. For the measured results and doing a weighted average it is obtained $95.27 \%$, close to the manufacturer data and higher than that of System I. The efficiency is higher despite having a LF transformer; it gives isolation but increases cost. For the used string arrangement and the $\mathrm{DC}$ and $\mathrm{AC}$ cabling it can be estimated losses of $0.10 \%$ and $0.27 \%$, respectively, at nominal power.

Several measurements, in different irradiation and temperature conditions were recorded in System III. For higher powers the efficiency slightly decreases; however, the absolute values are higher. According to the manufacturer, the system has a maximum efficiency of $96.4 \%$ and a Euro efficiency of $95.8 \%$; a weighted average of $95.82 \%$ was obtained. From all the analysed systems this is the one presenting the highest efficiency; it has a simple topology, with a single conversion stage and does not have a transformer. As shown in Table III, this microgeneration has a DC cable of 4 meters length and an $\mathrm{AC}$ cable of 120 meters; the PV installation is far from the grid. It is obtained very high AC losses, $79.39 \mathrm{~W}$ at nominal power and the total cable losses are $2.0 \%$, an unsatisfactory value. Only a thicker cable, more expensive, or a close connection to the grid could improve the installation efficiency.

\section{B. Comparative Results}

In nominal conditions, and for the three microgenerations, the following THD values for the injected grid current were recorded (Table IV).

Table IV. THD of the injected current in nominal conditions.

\begin{tabular}{cccc}
\hline & System I & System II & System III \\
\hline THD (\%) & 3.9 & 2.2 & 2.8 \\
\hline \hline
\end{tabular}

From the table, it can be concluded that System I is the one presenting the highest THD value. This value is due, mainly, to the presence of harmonics of order 3, 7 and 9 . These harmonics are hardly generated by the high 
frequency switching inverter; in principle they will be caused by the distortion of the grid voltage and a smaller $\mathrm{AC}$ inductance. In any case, however, any microgeneration presents THD values for the injected current smaller than the ones imposed by grid standards [11]-[12].

Table V summarizes the efficiency results, from manufacturers, measurements and estimations. The most efficient from the point of view of the PE conversion is System III, with an average efficiency of $95.8 \%$. However, the specific installation where it is used makes it not to be the globally most efficient system, leaving that position for the installation incorporating System II.

Table V. Comparative analysis of the efficiency.

\begin{tabular}{lccc}
\hline & System I & System II & System III \\
\hline Maximum (catalogue) & 94.3 & 95.6 & 96.4 \\
\hline Euro (catalogue) & 93.5 & 94.7 & 95.8 \\
\hline $\begin{array}{l}\text { Average of the } \\
\text { converter, (measured) }\end{array}$ & 93.7 & 95.3 & 95.8 \\
\hline $\begin{array}{l}\text { Average of the } \\
\text { installation, (estimat.) }\end{array}$ & 93.3 & 94.8 & 93.8 \\
\hline \hline
\end{tabular}

\section{Conclusion}

This paper presented the main characteristics of three PV installations based on different panels' arrangements, PE systems and grid connection. The losses models of the PE subsystems were presented and the obtained simulation results allowed concluding that the simplest topology has the highest efficiency. The two-stage topology, with DC/DC converter and HF transformer, has the lowest efficiency, and System II, including a LF transformer, is in the middle.

From the three analysed installations and because there are various subsystems where losses occur, the one presenting the best overall efficiency is System II. From the point of view of the PE, System III has the best inverter but, due to a larger distance to the grid, is the one presenting the highest conduction losses and therefore is not the best system. The factor "inverter efficiency" is one of the most important ones in a PV installation but the overall energetic efficiency depends on other factors also.

\section{References}

[1] B. Sahan, S.V. Araújo, T. Kirstein, L. Menezes, P. Zacharias, "Photovoltaic converter topologies suitable for SiC-JFETs", in Proceedings of PCIM Europe Conference (PCIM’2009), 12-14 May 2009, pp. 431-437, 2009.

[2] B. Burger, D. Kranzer, "Extreme high efficiency PV-power converters", in Proceedings of the $13^{\text {th }}$ European Conference on Power Electronics and Applications (EPE 2009), 8-10 Sept. 2009, Barcelona, Spain, 2009.

[3] C. Wilhelm, D. Kranzer, B. Burger, "Highly compact and high efficient solar inverter with silicon carbide transistors", in Proceedings of the $25^{\text {th }}$ European Photovoltaic Solar Energy Conference and Exhibition $/ 5^{\text {th }}$ World Conference on Photovoltaic Energy Conversion, 610 Sept. 2010, Valencia, Spain, pp. 4442-4447, 2010.

[4] W.N. Macedo, R. Zilles, "Operational results of gridconnected photovoltaic system with different inverter's sizing factors (ISF). Progress in Photovoltaics: Research and Applications, vol. 15, pp. 337-352, 2007.

[5] SMA, "Performance Ratio. Quality factor for the PV plant", Technical Information, SMA Solar Technology AG, 2010.

[6] N. Mohan, T. Undeland, W. Robbins, "Power Electronics. Converters, Applications and Design", $2^{\text {nd }}$ Ed., John Wiley and Sons, New York, USA, 1996.

[7] J. Rodriguez, L.G. Franquelo, S. Kouro, J.I. Leon, R.C. Portillo, M.M. Prats, M.A. Perez, "Multilevel converters: An enabling technology for high-power applications", Proceedings of the IEEE, vol. 97, no.11, pp.1786-1817, Nov. 2009.

[8] L.K. Meshta, P.D. Evans, "Analysis of on-state losses in PWM inverters", IEE Proceedings, Electric Power Applications, vol. 136, no. 4, pp. 189-194, 1989.

[9] F. Casanellas, "Losses in PWM inverters using IGBTs", IEE Proceedings, Electric Power Applications, vol. 144, no. 5, pp. 235-239, 1994.

[10] A. Khaligh, O.G. Onar, "Energy Harvesting. Solar, Wind, and Ocean Energy Conversion Systems", CRC Press, Boca Raton, USA, 2010.

[11] EN 50438, "Requirements for the connection of microgenerators in parallel with public low-voltage distribution networks", 2007.

[12] IEC, "IEC 61000-3-2. Electromagnetic compatibility (EMC): Limits for harmonic current emissions (equipment input current $<16$ A per phase)", 2000. 